\title{
An overview of current business analytics programs across US AACSB schools
}

\author{
Yilong " Eric" Zheng, Merrimack College, zhengy@merrimack.edu \\ Tahir Hameed, Merrimack College,hameedt@merrimack.edu \\ Raymond Lavoie, Merrimack College, lavoier@merrimack.edu \\ Patricia Sendall, Merrimack College,sendallp@merrimack.edu
}

\begin{abstract}
Business analytics education has been on the rise in business schools due to the interdisciplinary nature of the discipline and its prevalence for business applications in the industry. Despite the topic's popularity, very few studies have examined the current trends, existing degree programs, faculty, and their area of expertise for business analytics education at AACSB business schools from a holistic point of view. This pedagogical paper intends to provide relevant information and summarized statistics from the following four main areas: (I) A literature review of business analytics education trends in recent years and other commonly framed or related terms; (2) In terms of data, we reviewed the past 8 years of trends in business analytics education using the annual AACSB report, specifically in terms of the number of business analytics-related programs and positions offered; (3) An examination of each of the 500+ AACSB schools in the US and their undergraduate and graduate degrees offered in business analytics; and (4) A summary of the common areas of expertise and compositions of faculty teaching business analytics among schools offering such programs.
\end{abstract}

Keywords: business analytics education, program evaluation overview, degrees and skills of professors, US AACSB programs

\section{Introduction}

The area of data science, data analytics, business intelligence, and other related fields have become trendy in the past decade due to the fast development of computing power, data storage, and other technological advancements. Across disciplines, scholars have anticipated a rapid revolution of analytics and its application in the frontiers of business, engineering, life science, medicine and health care, and social science (Ahmad et al. 2017; Chen, Chiang, \& Storey, 2012; Davenport \& Patil, 2012; Davenport, 2013). From a job market perspective, there has been an increasing demand for data analytics workforce for supporting just business operations alone. In 2011, Manyika et al. from McKinsey consulting firm indicating that the job demand gap for data analytics and data science in business was between 140,000 and 190,000 by 2018. Burning Glass Technologies (2017) provided a prediction that by 2020 the job demand for data science-related positions will increase to $2,720,000$, about $15 \%$ from that in the year 2016 .

As one of the main drivers for the adoption of analytics practices, higher education has played an important role to educate future generations and provide necessary labor forces for the organizations. Specifically, within the domain of higher education, business schools are at the forefront of analytics education due to being closely connected to the application of data analytics for businesses. If we considered the general 


\section{Issues in Information Systems}

Volume 22, Issue 2, pp. 306-317, 2021

business analytics education field as a market, then business schools and companies can be considered each as the supply side and the demand side of the market, respectively. As much as we are aware of how companies are in desperate need of graduating students with critical business analytics skills from the perspective of the demand side, little is known how many and how well prepared such laborers can be educated and provided by the universities from the perspective of the supply side.

In the literature of business education, despite few studies that looked at the curriculum design and student reactions of analytics education at the college level across different disciplines, the attempt to systematically examine the education of analytics remains limited, let alone business analytics from the business school. Other than the important discussion of curriculum development, little has been examined regarding questions such as: How business schools are responding to the market demand of analytics and business analytics forces in terms of program offerings? Whether the number of programs being offered is up to the pace of analytics trends in recent years? Should business schools offer in-house analytics programs or rely on other similar programs (e.g. data science, data analytics, industrial engineering, information technology) from schools in a university? Whether there is already a saturation of business analytics in higher education? How many similar programs are currently offered at undergraduate vs. at graduate level vs. at the college level? Whether there are enough teaching forces and faculty to sustain the existing load of business analytics education from within the business school? What are the common education background and expertise of current educators teaching such business analytics courses in the business school?

In order to enrich the existing literature of analytics education and to help provide insights to these burning questions from the perspective of business schools, we conducted a program review in this pedagogical study through four main angles: (1) The examination of current literature of all the topics in analytics education. (2) Then, we adopted the established annual AACSB reports related to the topic of data analytics pedagogy and looked at the general trends of the business analytics program. (3) To provide an accurate and updated insight at the business school level in terms of degree and program offered, we collected empirical data from all the current AACSB schools across the US to identify how many business analytics related (degree offering) program are offered at both undergraduate and graduate level. (4) Lastly, to examine the education of business analytics further, we summarized the common education background and the area of expertise of current business analytics educators at the business schools. Through the data collection and exploratory examination of these data across AACSB schools, we hope to provide a "fundamental landscape picture" of current business analytics education in terms of trends, degrees, faculties, and their existing skills of data analytics education to the departments, the college administrators, the policymakers and beyond.

\section{Background and literature review}

\section{Current landscape of business analytics education}

Since 2012, literature on the curricula development for business analytics has also been on the rise, except two relevant papers by Johnson, et al. (2006) and McClure (2008) that mention the importance of having "computer literacy" and "quantitative literacy" for business school students. In Johnson et al. paper, the authors looked at both what the business school classes are covering for computer literacy, and how much confidence students had shown in their proficiency of computer tasks such as spreadsheeting, database literacy, and presentation skills. The results showed that there was an urgent need for developing a better curriculum plan for promoting students' learning in computer literacy. Similarly, when looking at the literature related to business analytics education in the past decade, there is a similar pattern emphasizing the need for promoting more analytics curriculum courses for business school students. There are several common findings across these curriculum studies: (1) Alternative curricula and academic infrastructure 


\section{Issues in Information Systems}

Volume 22, Issue 2, pp. 306-317, 2021

should be proposed for data science and data analytics education. (2) Data science education can be for all majors and should be interdisciplinary across different majors. (3) The industries are expecting more analytics forces, though good analysts are hard to get due to requiring a well-rounded skill and certain knowledge, which comes from extensive work experience. (4) Data analytics is becoming more industrial in scale, so the requirement is growing along with the demand.

Turel and Kapoor (2016) mentioned that the analytics skills gap is common across not just business analytics majors or professionals but all other business majors. Pan, et al. (2018) surveyed business industry experts and advisors (with a total of 93 responses) regarding what kinds of skillsets should be adopted by not only analytics majors but also other non-analytics business major students. The results from the survey indicated that "basic spreadsheet (86\%)", "intermediate spreadsheet (82\%)", "retrieving data (82\%)", "documenting data (92\%)" and "presenting data (96\%)" were the key skills that were required commonly across all business non-analytics majors. At an advanced degree or analytics major level, the important skills were: "basic statistics software (70\%)", "predictive statistics (64\%)", "advanced spreadsheet (62\%)", "intermediate statistics software $(60 \%)$ ", "database management $(48 \%)$ " and "programming statistics software (42\%)". The level statistical software is usually distinguished by different level of operations on the same software such as SAS, SPSS, STATA, or R. In terms of other skillsets, similar but more specific job skill requirements for data analytics and data science-related jobs are provided in Debortoli, Müller, and Vom Brocke (2014).

Besides the insights of business analytics education curriculum design and findings of analytical skill preparation in an analytics class, the literature about program offerings remains understudied as to its development and importance in general education in business schools. If the curriculum and skillset findings suggest a clear direction regarding how business schools should develop their courses and programs to prepare business students for their placement success in the job market, then how are the business schools preparing for such suggestions and changes in reality? Unfortunately, there is not yet a clear picture to help us with the current landscape of business analytics education. In the following section, we will focus on addressing the concerns of lacking insights as to how business schools are prepared for the adoption and changes of business analytics education to respond to such demand needs.

\section{Methodology}

\section{AACSB annual report}

To understand the overall quality and quantity of analytics education in comparison to the traditional business disciplines in the business school, we looked at the annual AACSB school reports (2014 - 2021) from the past 8 years available from the official AACSB website. The annual report provides aggregated information regarding the programs offered, the relative percentage of each program being offered at the undergraduate and graduate level, and tenure-track faculty compensation information across all international AACSB schools. These AACSB annual reports can provide a general outlook of the program development across all schools over time.

\section{AACSB school website and data scraping}

In addition to the AACSB annual report, we also conducted our own data collection process to collect the detailed program offering information (i.e. program by disciplines, degree types at undergraduate and graduate level) from each AACSB school. There was a total of 535 US AACSB accredited business schools according to the AACSB website (https://www.aacsb.edu/accreditation/accredited-schools), so we designed our data scraper to collect information from each of the US business schools. We did not collect 


\section{Issues in Information Systems}

Volume 22, Issue 2, pp. 306-317, 2021

data from all 901 accredited business institutions due to the concern of languages of international school websites, but we believe a sample of 535 (roughly 60\%) would provide a good representation of business schools. Specifically, information such as page links for undergraduate degrees, graduate degrees, degree descriptions, faculty directories page links was collected via our self-programmed data scraping tool. Depending on the level of detail provided by each school on their webpage, we were also able to collect course curriculum information for the business analytics degree. When collecting information from all 535 schools, we did not include information about business analytics certificate or minor programs in our data collection process given that these programs are not offering specific degrees. However, such non-degree programs were widely offered across AACSB schools. These data can provide a more updated overview of the existing programs across all AACSB schools, which may not have been captured by the official AACSB report.

Once the data collection process was finished for all US AACSB schools, a round of data cleaning and text analysis was conducted for all the descriptions to see what kind of business analytics program(s) are offered and if more than one analytics related program was offered from within each business school. For further analysis, we extracted the number of business school offerings in programs that included the word "analytics", the program with the name "data analytics", "Business Intelligence", or "Information Systems" which we believed were the most similar program offerings compared to "business analytics". In addition to that, if available, we also extracted the programs offered at the college level across all schools. Then, we extracted the program names "Data Science", "Information Technology", and "Information Science". These data points, when being summarized at the aggregate level, should provide a distribution of program numbers in frequencies.

After extracting the information about degree offerings from the previous step and identifying the undergraduate programs that offered business analytics curricula, our next step for data collection via programmed data scraping was to look at the faculty credentials. The analysis considered their highest degree earned (if available), year of receiving the highest degree (if available), their degrees earned since college (if available), and research and teaching interests (if available). For this round of data collection, we went through AACSB schools offering business analytics degrees at the undergraduate level and looked at the department in charge of offering business analytics courses. Across all the undergraduate schools offering business analytics degrees $(\mathrm{N}=105)$, we looked at the directory and collected the faculty information from these schools. There were on average 17 faculty members per school, with a minimum of 1 faculty, and a maximum of 85, except for a couple of schools (e.g. Hult International Business School, Syracuse University, University of South Florida) who did not clearly indicat faculty numbers or department directly responsible for offering business analytics courses.

\section{Results}

\section{Results of AACSB annual reports}

Upon examination of all the annual reports from the past 8 years, we found several important insights. In the 2014 AACSB report, there was no business school offering a degree program in analytics. This changed in the 2019 report, indicating that there were over 20 institutes offering tenure-track positions for faculty, and the business analytics programs accounted for $1.8 \%$ of all business degree programs at the undergraduate level, and $8.4 \%$ at the master's level. In the 2020 report, the corresponding numbers increased to 23 institutes, $5.3 \%$ at the undergraduate level, and $16.1 \%$ at the master's level. In the 2021 report, the most recent updates were 27 institutions, and $7.8 \%$ at the undergraduate level, and $19.4 \%$ at the graduate level. This information, when compared with Andoh-Baidoo et al. (2014)'s finding on related courses offered back in 2014, showed a significant increase in just 6 years. 


\section{Issues in Information Systems}

Volume 22, Issue 2, pp. 306-317, 2021

In terms of faculty hiring for data analytics programs, the AACSB report indicated that there were 64 tenuretrack positions across AACSB schools in the 2019 report, 90 tenure-track positions in the 2020 report, and 121 tenure-track positions in the 2021 report. The findings from the AACSB program report in terms of analytics programs offered indicated that there has recently been a rapid speed of development for the business analytics discipline at the AACSB schools in both degree offerings and faculty hiring. The rate of development in terms of rate of increase was among the fastest-growing programs besides entrepreneurship and hospitality management. However, the relative size of business analytics programs remains small as compared to other traditionally popular programs such as Finance, Accounting, Management, Marketing, and Economics.

\section{Results of AACSB school data}

In order to understand how different these seven different analytics related programs (i.e. Business Analytics, Data Analytics, Business Intelligence, Information Systems, Data Science, Information Technology, and Information Science) that are offered across all US AACSB schools at an aggregated level, we summarized the corresponding total count information of these programs in Table 1 below.

In terms of the overall distribution of these analytics programs, we found that more than half of the schools offered analytics degrees (bachelor's degree in business analytics, business administration with business analytics concentration), other analytics degrees (e.g. accounting analytics, marketing analytics) and nondegree (certificate, minor in business analytics) related programs. Over $65 \%(\mathrm{~N}=211)$ of the AACSB schools are offering a degree in business analytics concentrations at either undergraduate, graduate, or both levels.

Across all the programs offered, we found that there was a clear distinction between business analytics and information systems in terms of having a higher number of degree programs offered. Most schools would offer these two degrees simultaneously but not Data Analytics $(\mathrm{N}=68)$ and Business Intelligence Program $(\mathrm{N}=14)$, which indicates potential cannibalization between the business analytics program and the two less popular programs Data Analytics and Business Intelligence. Based on crosstab results, this was confirmed in Table 2. For instance, within each business school, when a business analytics program is offered, there are only 11 out of $109(10 \%)$ and 2 out of $109(2 \%)$ that a Data Analytics or Business Intelligence programs are offered. However, the number of Information Systems programs offered given the existence of a business analytics program at the same time was 72 out of $109(66 \%)$. If we considered similar programs offered outside the school of business, we could see that only 12 out of 109 (11\%) of the Data Science programs offered, indicating a similar cannibalization effect between business analytics and Data Science as well.

In order to understand the cases for more than one of these seven analytics-related programs (i.e. Business Analytics, Data Analytics, Business Intelligence, Information Systems, Data Science, Information Technology, and Information Science) that were offered simultaneously, we counted the sampling distribution of all these cases at undergraduate business schools, graduate business schools, and university level (see Figure 1). We found that across all AACSB schools, in terms of similar degree offerings, under two similar programs ( 2 programs, 1 program, or none) were the most common cases observed. However, there were still a few business schools offering more than two similar programs at the same time at the undergraduate level $(\mathrm{N}=13)$ and the graduate level $(\mathrm{N}=25)$. 
Table 1. Number of Analytics Related Programs Offered in AACSB Accredited Universities

\begin{tabular}{|c|c|c|c|c|c|c|c|c|}
\hline \multirow{2}{*}{$\begin{array}{l}\text { School Types } \\
\text { Program Name }\end{array}$} & \multicolumn{5}{|l|}{ Under Business School } & \multicolumn{3}{|c|}{ Under Other Schools } \\
\hline & $\begin{array}{l}\text { Contains Analytics" } \\
\text { (Including } \\
\text { Certificates, Minor) }\end{array}$ & $\begin{array}{l}\text { Business } \\
\text { Analytics }\end{array}$ & $\begin{array}{l}\text { Data } \\
\text { Analytics }\end{array}$ & $\begin{array}{l}\text { Business } \\
\text { Intelligence }\end{array}$ & $\begin{array}{l}\text { Info } \\
\text { Systems }\end{array}$ & $\begin{array}{l}\text { Data } \\
\text { Science }\end{array}$ & $\begin{array}{l}\text { Info } \\
\text { Tech }\end{array}$ & $\begin{array}{l}\text { Info } \\
\text { Science }\end{array}$ \\
\hline Offered & 273 & 211 & 68 & 14 & 285 & 51 & 124 & 36 \\
\hline Not Offered & 262 & 324 & 467 & 521 & 250 & 484 & 411 & 499 \\
\hline
\end{tabular}

Table 2. Cross-tabulation of Different Undergraduate Analytics Related Programs Offered Within University $(\mathbf{N}=\mathbf{5 3 5})$

\begin{tabular}{lllllllllll}
\hline Business Analytics & \multirow{2}{*}{ Analytics } & $\begin{array}{l}\text { Data } \\
\text { Analytics }\end{array}$ & \multicolumn{2}{l}{$\begin{array}{l}\text { Business } \\
\text { Intelligence }\end{array}$} & $\begin{array}{l}\text { Info } \\
\text { Systems }\end{array}$ & \multicolumn{2}{c}{$\begin{array}{l}\text { Data } \\
\text { Science }\end{array}$} \\
\hline \multirow{3}{*}{ Offered } & Yes & No & Yes No & Yes & No & Yes & No & Yes & No \\
\cline { 2 - 12 } Not Offered & 109 & 0 & 11 & 98 & 2 & 107 & 72 & 37 & 12 & 97 \\
\hline
\end{tabular}

Table 3. Business Analytics Faculty Highest Degree Earned by Levels $(N=1540)$

\begin{tabular}{llllll}
\hline \multicolumn{2}{l}{ Doctoral ( PhD, JD, ED, DBA, DSC) } & Masters ( MBA, MA, MS, MSP) & \multirow{2}{*}{ Bachelor Unclear } \\
\hline Ph.D. & Other Doctoral & MBA & Other Master's & & \\
\hline 1075 & 110 & 69 & 74 & 7 & 205 \\
\hline
\end{tabular}




\section{Issues in Information Systems}

Volume 22, Issue 2, pp. 306-317, 2021

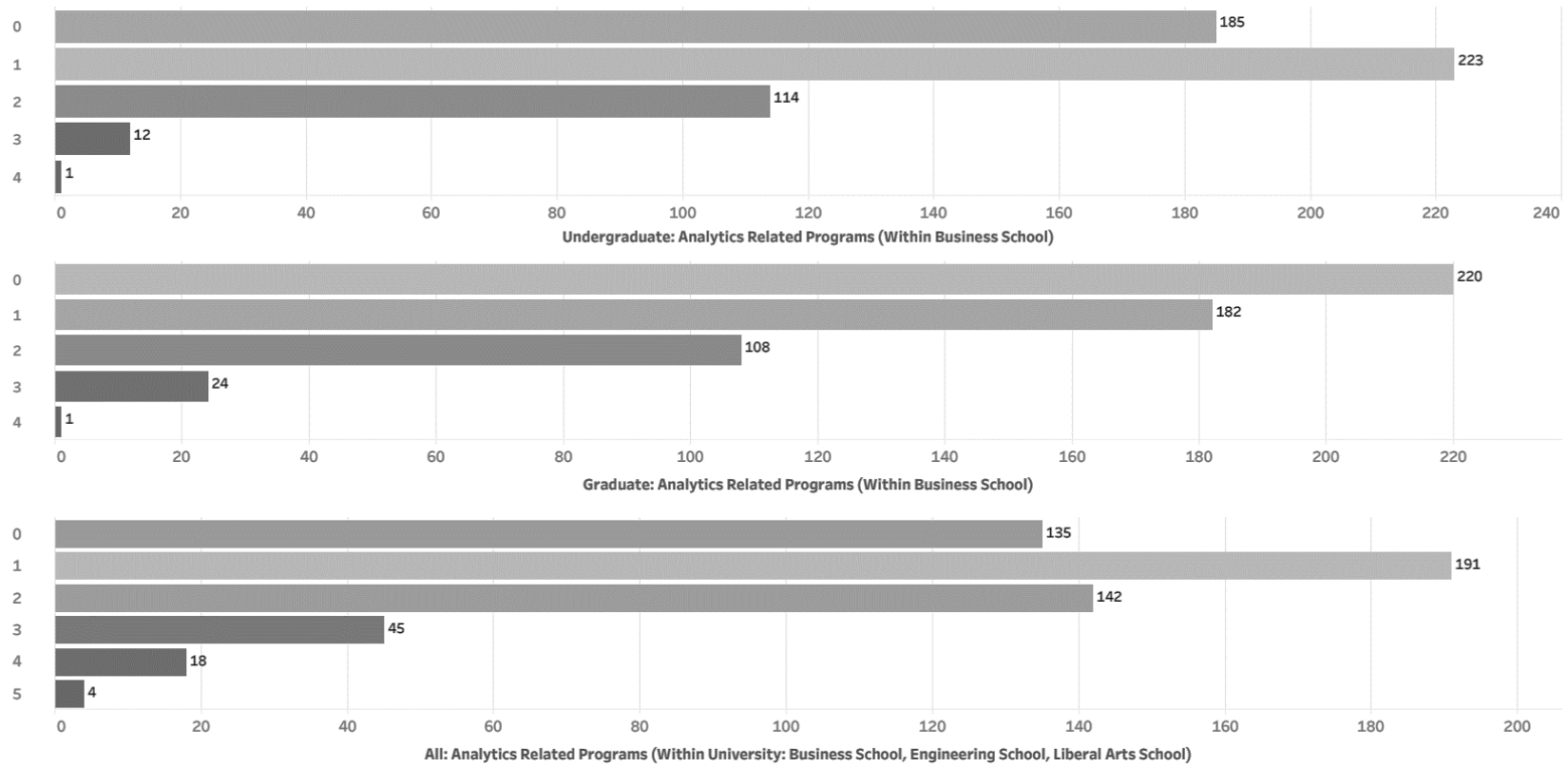

Figure 1. Number of Analytics Related Programs Offered at Different Levels

( $N$ = 535 AACSB Certified University)

\section{Results of AACSB school faculty background \& area of expertise}

A separate analysis was conducted at the faculty level based on AACSB schools who offered an undergraduate degree in business analytics $(\mathrm{N}=109)$. As a result, faculty information from a total of 105 schools was collected, except for four schools who did not clearly indicate the teaching forces for their business analytics-related courses on the school website. A total of 1540 faculty profiles were recorded. Some of the profiles contained only partial information given then that they were unavailable on the school websites. The purpose of examining the teaching forces of business analytics education via the lens of faculty training background and area of expertise was to provide a different angle for understanding the faculty composition in the business school for teaching the subject of analytics. We understand this was certainly not a direct measure of teaching competencies as teaching evaluations or directly examining the placement rate of teaching forces across schools, but our attempt was certainly for understanding a different aspect of teaching forces that traditional pedagogical papers might often overlook. We believed the education background, regardless of tenure track or non-tenure track, full-time or part-time, could indicate a degree of experience or subject matter expertise of an instructor. The summary results of degree disciplines across all instructors at these 105 AACSB schools could help us to understand which disciplines have been supplying educators for business analytics, and a general understanding of whether students are getting a more technical-oriented or theoretical-oriented education based on the instructor's background. Given the exploratory nature of this study, the results did not intend to send any signal regarding a significant or direct link between one's educational background and the teaching outcome in business analytics. After all, business analytics is a highly interdisciplinary field that is not bounded by any specific subject domain.

Our data collected from these 105 business school samples indicated that most instructors had previously obtained a doctoral-level degree $(\mathrm{N}=1185)$, followed by a master's level degree $(\mathrm{N}=143)$ and bachelor level degree $(\mathrm{N}=7)$, with 205 profiles being unclear what highest level of degree received by the instructor. A detailed summary of faculty count is provided in Table 3 . 


\section{Issues in Information Systems}

Volume 22, Issue 2, pp. 306-317, 2021

In terms of the most common subject domain of these analytics courses instructors, we could clearly see in Figure 2 that Information Systems $(\mathrm{N}=182)$, Operation Management $(\mathrm{N}=113)$, and Economics $(\mathrm{N}=58)$ were the top 3 subject domains for sustaining the current education of business analytics. Out of the top 16 subject domains illustrated, most of the disciplines of faculty are business or economics-related (more than 10 out of 16), except the most popular non-business or non-economics related degrees being industrial and operations engineering $(\mathrm{N}=51)$, statistics $(\mathrm{N}=47)$, and computer science $(\mathrm{N}=27)$. If we combined statistics with mathematics, then the most popular non-business-related degree would be statistics, applied mathematics, and mathematics-related. It is worth mentioning that out of all the degrees (including lowerlevel degrees) sought by the instructors, there was a good number of educators coming from an engineering background ( $\mathrm{N}=235$ out of 1540$)$ to potentially provide different kinds of business analytics education to students, compared to instructors only trained in the business background ( $\mathrm{N}=638$ out of 1540).

As to the years to the date of their degree earned, we can see that most instructors received their highest degree between 2010 and 2020. Although being clearly straightforward, we could still see that the number of teaching forces is relatively young with at least 5-10 years of experience in the field of practice. The relative number of degrees offered by decades is growing over time, matching with the number of degrees offered in general.

To explore faculties' aggregated areas of expertise, we conducted text analysis and extracted the most common keywords of their research and teaching interests and created two word clouds (Figure 2). As can be seen from these visualizations, the bigger the word size, the more frequently each word was mentioned by the faculty in general. It is clear that "Business", "Data", "Operations", "Information", "Systems", "Analytics", "Analysis", "Statistics" were among the top of the list for research interests and a similar group of words for teaching interests. In addition to the words mentioned, words such as "Database", "Machine", "Mining", "Learning", "Modeling", "Healthcare" related topics were on top of the list as well.

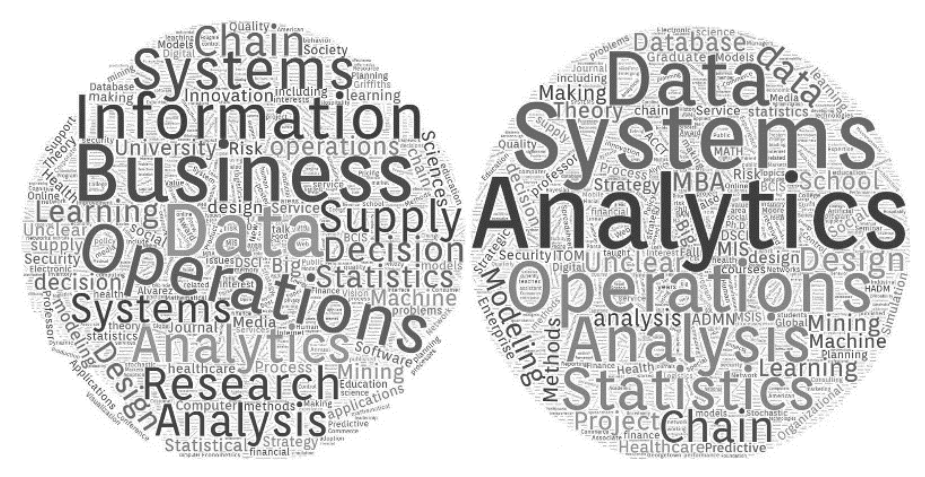

Figure 2. Word Cloud Summary of Faculty Research (Left) \& Teaching (Right) Interests

\section{Discussion}

In this pedagogical study, we collected and analyzed data related to business analytics programs offered across AACSB accredited business schools, hoping to provide a general understanding of the current business analytics landscape in terms of trends, degree programs offered, teaching faculty, and faculty expertise. Through our exploratory analysis of all 535 US AACSB business schools and over 1500 faculty 


\section{Issues in Information Systems}

Volume 22, Issue 2, pp. 306-317, 2021

profiles, we were able to create some general insights as to how business analytics education has been growing in the past $5-10$ years as a new domain. We questioned whether there was potential for cannibalization and competition within business schools and across universities who offered similar kinds of analytics programs, and finally, how ready our teaching forces are prepared in terms of educational background and level of subject matter. Through the examination of empirical data collected from established AACSB reports and data from scraping through a variety of business school websites, we were able to respond to several initial questions addressed in the introduction section, such as "How are business schools responding to the market demand of analytics and business analytics forces in terms of program offerings?"; "Should business schools offer in-house analytics programs or rely on other similar programs (e.g. data science, data analytics, industrial engineering, information technology) from schools in a university?"; "Is there already a saturation of business analytics in higher education?"; "How many similar programs are currently offered at undergraduate vs. at graduate levels?"; and "What are the common education background and expertise of current educators teaching such business analytics courses in the business school?"

Through a different approach of looking that the teaching forces of business analytics education, we provided some first-hand program and faculty-level insights as to how current business analytics education is being offered at AACSB business schools. There were significantly more programs being offered across business schools than the number reported in the most recent report from AACSB. Out of all the 535 business schools, the number of degree-seeking and non-degree seeking business analytics related programs are already over $50 \%$ of the population. There are a few schools that even offer more than two similar kinds of analytics programs within business schools or across universities, which indicated that there are potentially more extensions of business analytics in the business disciplines. The results also indicated that the potential cannibalization effect at various levels, including the competition between undergraduate programs and graduate programs, the competition between programs from within the business school and across different schools or in the same university may gradually become a common problem for administrators.

Despite seeing the number of programs and number of faculty growing at a promising speed, we are still not sure if there is a direct link between the number of programs being offered and the number of students intended to pursue a business analytics degree, and eventually whether the gap in demand is going to be filled in the near future. This was due to the exploratory nature of the study and the lack of critical information from the perspective of student enrollment and job placement outcomes from all of these programs. However, from strictly the supply-side, we could certainly see that there is a positive trend for adopting business analytics education across business schools. From the perspective of the discipline, we saw that the traditional subjects such as information systems and operation management are still the main training field for supplying the educating forces for business analytics, yet other business disciplines are yet to catch up despite the fast adoption of analytics in the field of marketing, accounting, and finance. Although not always the case, a potential concern of domain-restricted education in current business analytics education may create a bottleneck effect for the need of the right kind of training among students in other domain-specific fields.

As to the implication of the current study in policy-related decisions, we hope to bring awareness to the importance of business analytics education to fulfill the increasing gap between supply and demand. We encourage business school administrators to take a closer look at the curriculum, the enrollment, and placement of their business analytics program to see if offering more than two similar analytics programs (whether degree-seeking or non-degree seeking) can create a potential cannibalization effect at the business school level. Logically, it may make sense to cover different kinds of analytics program due to the interdisciplinary nature of analytics education. We also hope to bring awareness to business school 


\section{Issues in Information Systems}

Volume 22, Issue 2, pp. 306-317, 2021

administrators regarding the potential competition from other schools such as engineering and liberal arts schools, as this may create cannibalization of student enrollment. A more continuous and "sticky" education journey or degree-seeking plan may be created to compete with other programs outside the school of business.

Like other studies, the current study certainly contains several major limitations worth mentioning: (1) Our attempt to explore all the business analytics program was certainly not exhaustive, simply considering the fact that text analysis on the program names and faculty area of expertise may be slightly biased due to missing cases or the case of miscounting (e.g. double count due to program name including both terms together as a name; or missing the count due to different wording of programs that can be analytics in nature such as big data analytics, data $\&$ analytics, or computer information analytics). (2) The results provided a general idea as to the proportion of the degree distribution across teaching forces, but certainly could suffer from another potential bias due to the lack of information. Not all schools are offering sufficient education background on every adjunct, part-time professor, $\mathrm{Ph} . \mathrm{D}$. student, or teaching assistant on the school websites, yet these parties may also be part of the business analytics teaching forces as well. Also, it is likely that some of these instructors had previously taught analytics related course but are no longer teaching the courses, or some cases, instructors may be teaching courses not directly related to analytics but were classified into the department in charge of teaching analytics (e.g. accounting professors in Accounting Information Systems or Analytics department, operations research or information systems professors not teaching analytics related course but many other colleagues in the department are). (3) Our study may provide limited insights or limitations as some of this information could be confirmed by experience. However, the hindsight effect could be in play and significantly reduced the potential implication of the results despite the labor-intensive data collection process.

Future studies on similar research topics could elaborate on more quantitative data such as enrollment and placement data to provide a more complete picture of how well in general the business analytics education is, from the angle of a supply-side. We would also encourage future studies to take an even closer look at the curriculum offered at each of these 535 AACSB schools and see if the courses offered are sufficient and fitting the needs of organizations. Certainly, a more comprehensive review of factors influencing business analytics education is encouraged as well due to the need for examining the effectiveness of such new interdisciplinary programs in the business school.

\section{References}

AACSB. (2014). 2014 Business School Data Guide. Retrieved from: https://www.aacsb.edu/ /media/AACSB/Publications/data-trends-booklet/2014.ashx.

AACSB. (2015). 2015 Business School Data Guide. Retrieved from: https://www.aacsb.edu//media/aacsb/publications/data-trendsbooklet/2015. ashx?la=en\&hash=376DA4AE00ECB5AD32C468F788542D7A62D78CA5.

AACSB. (2016). 2016 Business School Data Guide. Retrieved from: https://www.aacsb.edu//media/aacsb/publications/data-trends-booklet/2016.ashx?la=en. 


\section{Issues in Information Systems}

Volume 22, Issue 2, pp. 306-317, 2021

AACSB. (2017). 2017 Business School Data Guide. Retrieved from: https://www.aacsb.edu/$/ \mathrm{media} / \mathrm{aacsb} / \mathrm{publications/data-trends-}$

booklet/2017.ashx?1a=en\&hash=AE844695D43E07D71F49A14210EB491D2CBE52E5.

AACSB. (2018). 2018 Business School Data Guide. Retrieved from: https://www.aacsb.edu/$/ \mathrm{media} / \mathrm{aacsb} / \mathrm{publications/data-trends-}$

booklet/2018.ashx?la=en\&hash=D38952C6CF98C3A24A6D32EB5313696D6D5D6B9A.

AACSB. (2019). 2019 Annual Report. Retrieved from: https://www.aacsb.edu/$/$ media/aacsb/publications/data-trends-

booklet/2019.ashx?la=en\&hash=84E51D3E6928ECADF6E8D51D41E64C0D58ED48B8.

AACSB. (2020). 2020 Annual Report. Retrieved from: https://www.aacsb.edu/-/media/aacsb/publications/datatrends-booklet/2020.ashx?la=en\&hash=DD37BBF79457F638BBB43C19A72F1840121796D6.

AACSB. (2021). 2021 Annual Report. Retrieved from: https://www.aacsb.edu/-/media/aacsb/publications/datatrends-

booklet/business\%20school\%20data\%20guide\%202021.ashx?la=en\&hash=EB2DA8ADA604D1F23457F5 3C1C4362E284081741.

Ahmad, H. M., Anwar, Z., \& Ali, M.S. (2017). Data Mining Techniques and Applications - A Decade Review. 23rd International Conference on Automation and Computing (ICAC), Huddersfield, pp. $1-7$.

Andoh-Baidoo, F. K., Villa, A., Aguirre, Y. \& Kasper, G. M. (2014). Business Intelligence \& Analytics Education: An Exploratory Study of Business \& Non-business School IS program Offerings. In 20th Americas Conference on Information Systems, AMCIS 2014.

Burning Glass Technology (2017). Job post estimates include actual job growth, job replacements, and churn. Retrieved from: https://www.burning-glass.com/

Chen, H., Chiang, R. H. L., \& Storey, V. C. (2012). Business Intelligence and Analytics: From Big Data to Big Impact. MIS Quarterly: Management Information Systems, 36(4), 1165-1188.

Davenport, T. H. (2013). Analytics 3.0. Harvard Business Review, December 2013. Retrieved from https://hbr.org/2013/12/analytics-30.

Davenport, T. H., \& Patil, D. J. (2012). Data Scientist: The Sexiest Job of the 21st Century. Harvard Business Review, 70-76. 


\section{Issues in Information Systems}

Volume 22, Issue 2, pp. 306-317, 2021

Debortoli, S., Müller, O., \& Vom Brocke, J. (2014). Comparing Business Intelligence and Big Data Skills: A Text Mining Study Using Job Advertisements. Business \& Information Systems Engineering, 6(5), 289-300.

Johnson, D. W., W. Bartholomew, K., \& Miller, D. (2006). Improving Computer Literacy of Business Management Majors: A Case Study. Journal of Information Technology Education: Research, 5, 077-094.

Manyika, J., Chui, M., Brown, B., Bughin, J., Dobbs, R., Roxburgh, C., Byers A. H. (2011). Big Data: The Next Frontier for Innovation, Competition, and Productivity. McKinsey Digital, retrieved from https:/www.mckinsey.com/business-functions/mckinsey-digital/our-insights/big-data-the-nextfrontier-for-innovation

McClure, R., \& Sircar, S. (2008). Quantitative Literacy for Undergraduate Business Students in the 21st Century, Journal of Education for Business, 83:6, 369-374, DOI:10.3200/JOEB.83.6.369-374

Pan, K., Blankley, A. I., Mazzei, M. J., Lohrke, C. F., Marshall, J. B., \& Carson, C. M. (2018). Surveying Industry Advisors to Select Data Analytics Topics for All Business Majors. The International Journal of Management Education, 16(3), 483-492.

Turel, O., \& Kapoor, B. (2016). A Business Analytics Maturity Perspective on the Gap Between Business Schools and Presumed Industry Needs. Communications of the Association for Information Systems, 39, 96-109. 